\title{
El ciclo de vida del producto
}

1. Concepto y características del ciclo de vida del producto

2. Análisis estratégico a través del ciclo de vida del producto

3. Estrategias para alargar el ciclo de vida del producto

Inmaculada Gallego Galán

igallego@uma.es

Dpto. Economía y Administración de Empresas 


\section{Objetivos:}

- Conocer la evolución de los productos a través de las distintas etapas por las que va pasando

- Analizar las características y objetivos de marketing en cada fase.

- Estudiar cómo debe responder el marketing en cada una de esas etapas. 


\section{Concepto y características del ciclo de vida del producto}




\section{Ciclo de vida del producto:}

El comportamiento del mercado, la situación del entorno y la competencia cambian a lo largo del tiempo en el que el producto se comercializa.

Estos cambios condicionan el diseño y afectan al desarrollo de la estrategia de marketing.

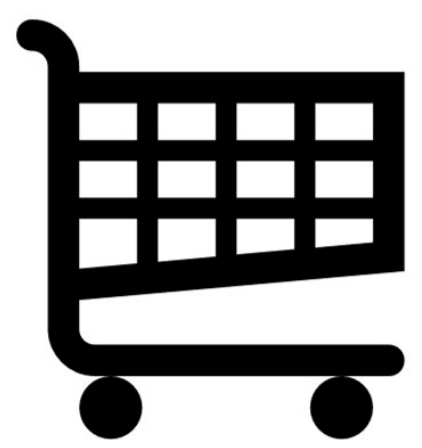


El concepto de ciclo de vida del producto ayuda a los profesionales del marketing a interpretar la dinámica del producto y del mercado.

U Herramienta para la toma de decisiones.

Modelo general, pero existen numerosas variantes.

A Aplicable a distintos niveles de análisis: categorías de productos, formas, productos y marcas. 
DEBATE: El ciclo de vida del producto es....

A. una variable dependiente que viene determinada por la acciones de marketing.

B. Una variable independiente a la que las empresas deben adaptar sus acciones de marketing.
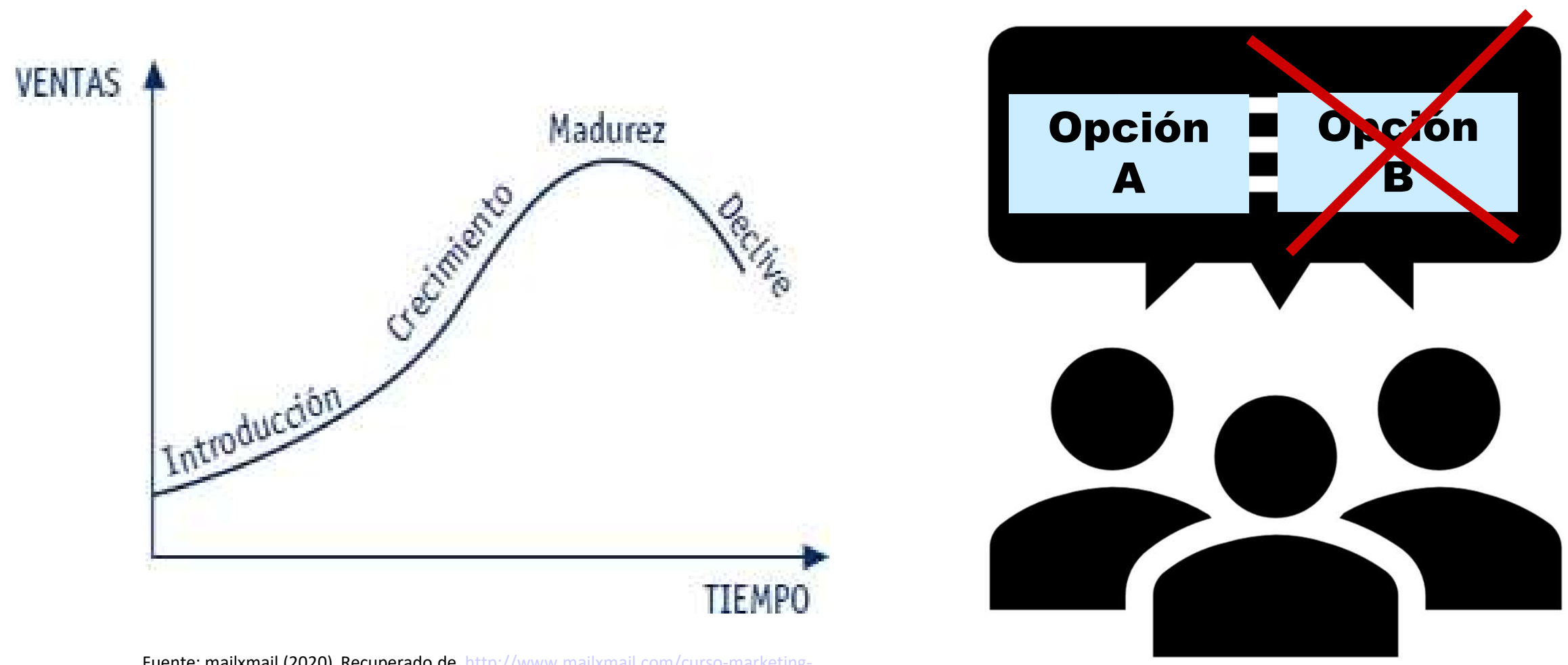

Fuente: mailxmail (2020). Recuperado de 


\section{Entender el ciclo de vida es entender que.......}

$>$ Los productos tienen una vida limitada

$>$ Las ventas de un producto atraviesan distintas fases, y cada una de ellas presentan diferentes desafíos, oportunidades y problemas

$>$ Los beneficios aumentan y disminuyen en las diferentes fases

$>$ Los productos requieren diferentes estrategias en cada una de las fases 


\section{Fases del ciclo de vida del producto:}

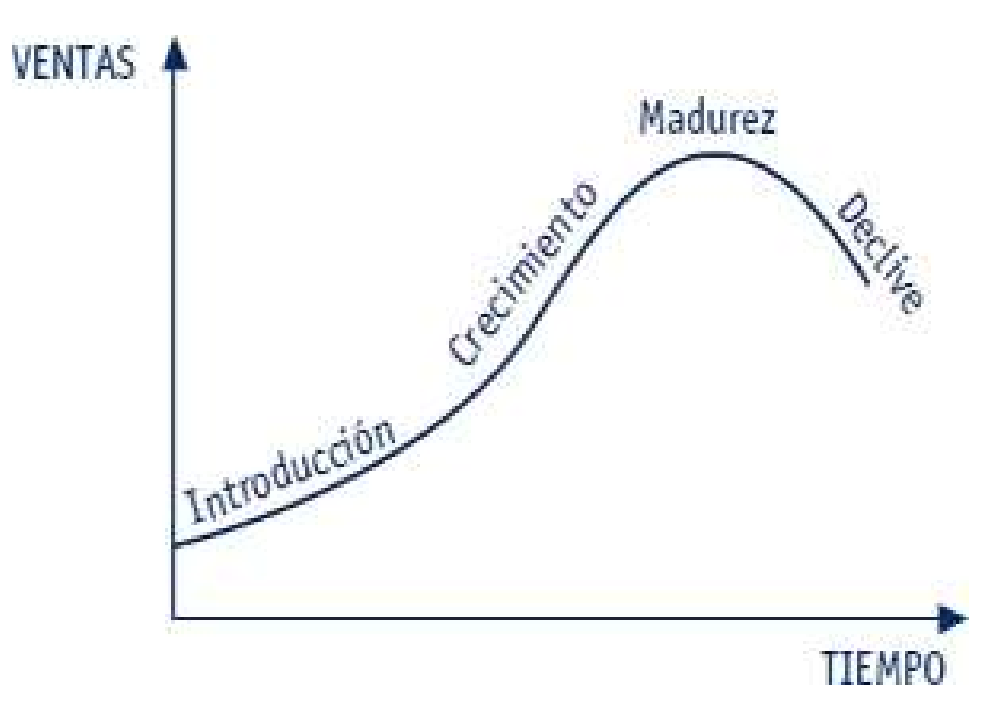

INTRODUCCIÓN: crecimiento lento de ventas, no existen beneficios debido a los fuertes gastos que conlleva el lanzamiento del producto.

Su duración depende de:

- La complejidad del producto

- Del grado de novedad

- Influencia de la moda

- Del mayor o menor ajuste a las necesidades del consumidor

- Número de personas que intervienen en la compra

- Presencia o no de sustitutos competitivos 


\section{Fases del ciclo de vida del producto:}

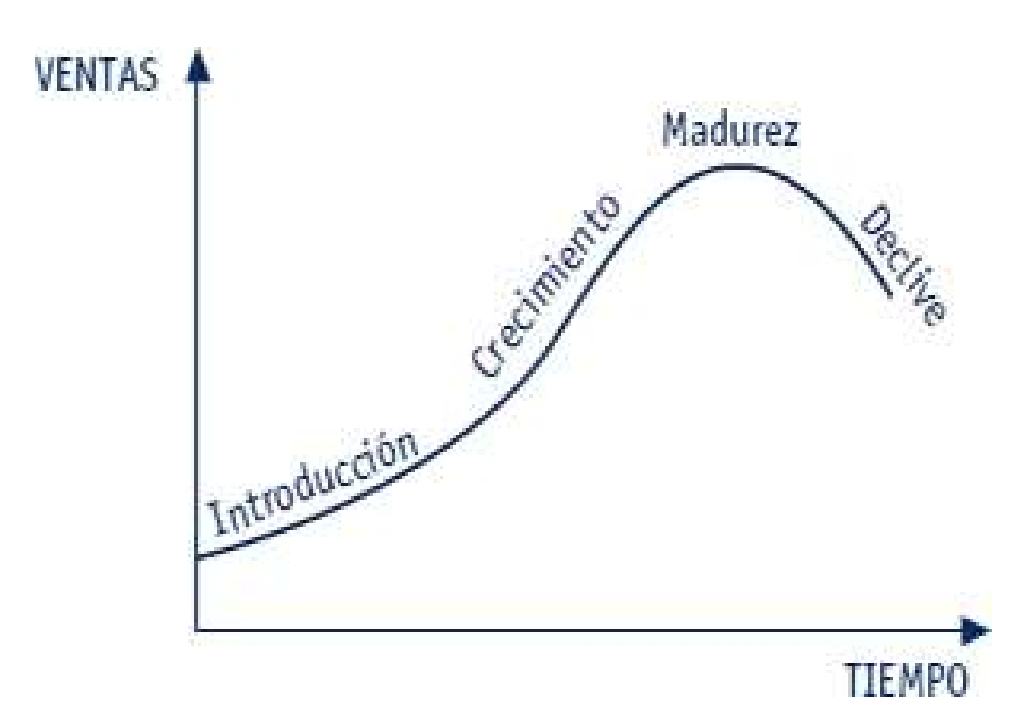

Fuente: mailxmail (2020). Recuperado de
INTRODUCCIÓN: crecimiento lento de ventas, no existen beneficios debido a los fuertes gastos que conlleva el lanzamiento del producto.

+ Características de esta etapa:

- Los competidores son escasos o incluso inexistentes.

- Se ofrecen versiones básicas del productos

- Lo adquieren los consumidores más innovadores.

- Precio suele ser alto 


\section{Fases del ciclo de vida del producto:}

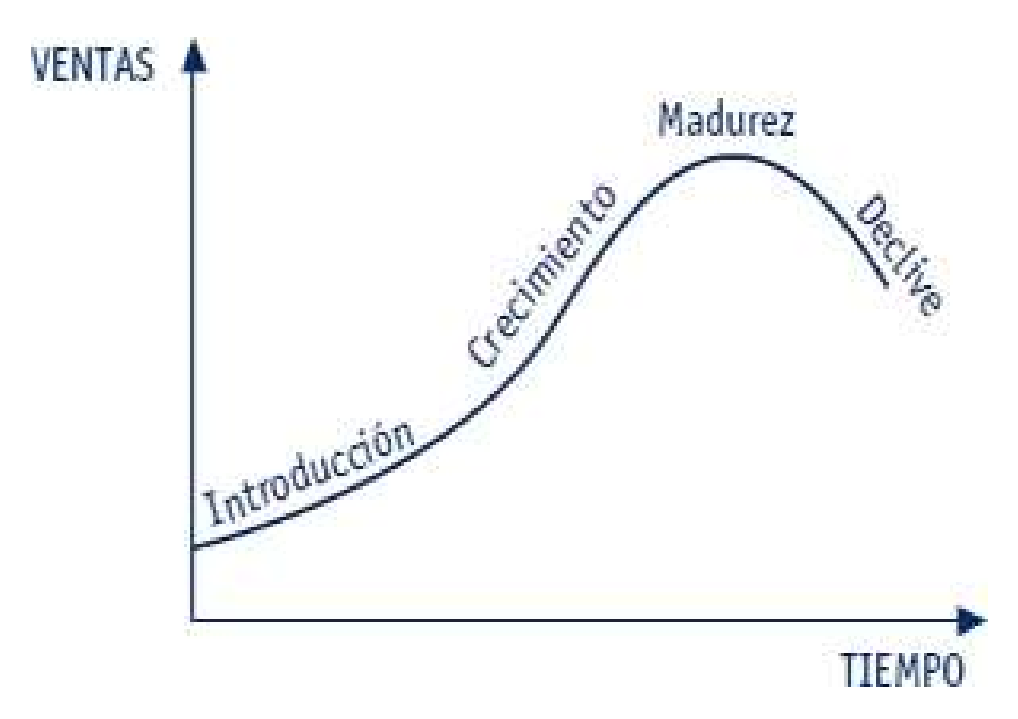

Fuente: mailxmail (2020). Recuperado de
CRECIMIENTO: aceptación rápida del producto por el mercado en el que los beneficios aumentan considerablemente.

+ Características de esta etapa:

- La competencia se intensifica.

- Los primeros consumidores llevan a cabo un proceso de difusión que atrae a la mayoría de compradores.

- Aumenta el número de versiones del producto.

- Mejoran las prestaciones.

- Precio es alto pero comienza a bajar. 


\section{Fases del ciclo de vida del producto:}

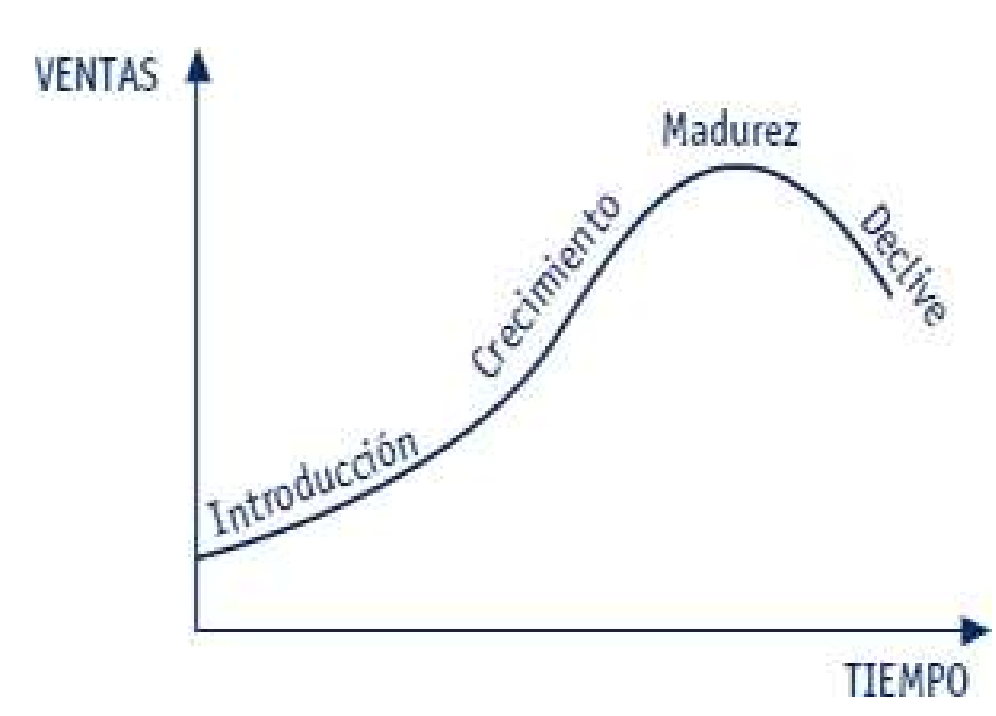

MADUREZ: La demanda se mantiene por reposición del producto o nuevas familias entre consumidores

+ Características de esta etapa:

- Es la fase más larga.

- La mayoría de los productos se encuentran en ella.

- Su duración se debe alargar con estrategias.

- Poca diferenciación entre productos.

- Competencia en precio intensa.

- Más servicios asociados al producto. 


\section{Fases del ciclo de vida del producto:}

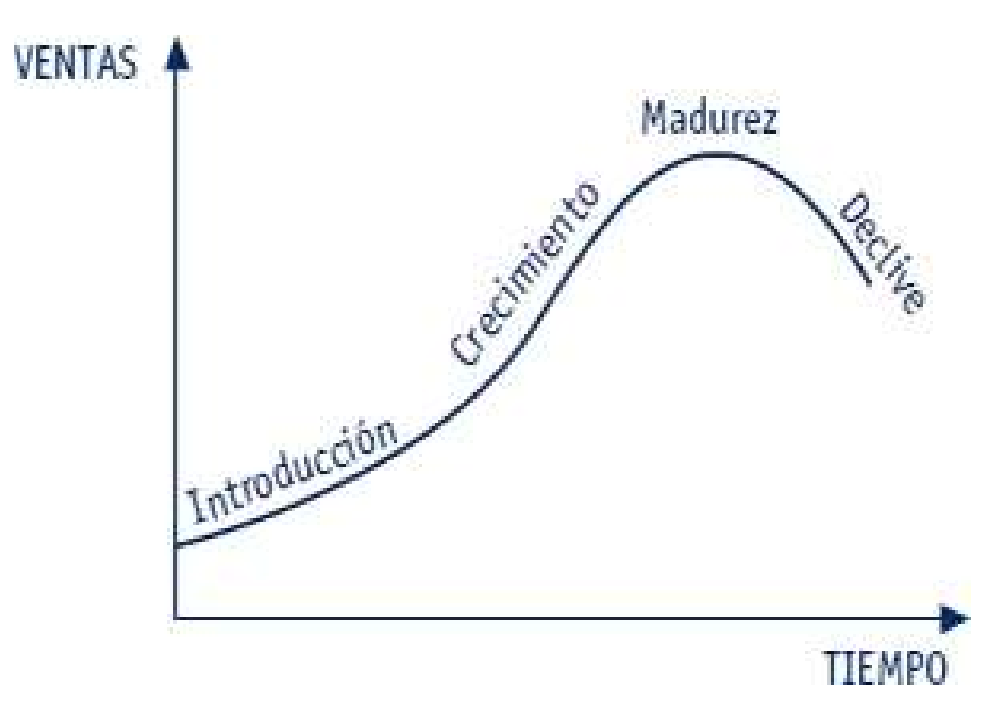

Fuente: mailxmail (2020). Recuperado de
DECLIVE: las ventas bajan y los beneficios disminuyen rápidamente.

Razones disminución ventas:

- Avances tecnológicos.

- Cambios en los gustos y modas.

- Pérdida de competitividad.

- Productos alternativos más económicos, duraderos, seguros o con prestaciones superiores.

- Etc.

+ Características de esta etapa:

- Poca variedad de productos

- Los precios se estabilizan e incluso llegan a subir

- Menor competencia

- Búsqueda de alternativas (sustitución, rediseño, nuevos usos, etc.) 
La decisión de retirar definitivamente un producto

- mantenerlo durante más tiempo dependerá de:

a Posibilidades de sustitución por otro más rentable.

๑ Posibilidad de rediseñar el actual.

Encontrar nuevos usos al producto.

Atraer nuevos usuarios.

$\square$ Retirada de los competidores 


\section{Fases del ciclo de vida del producto:}

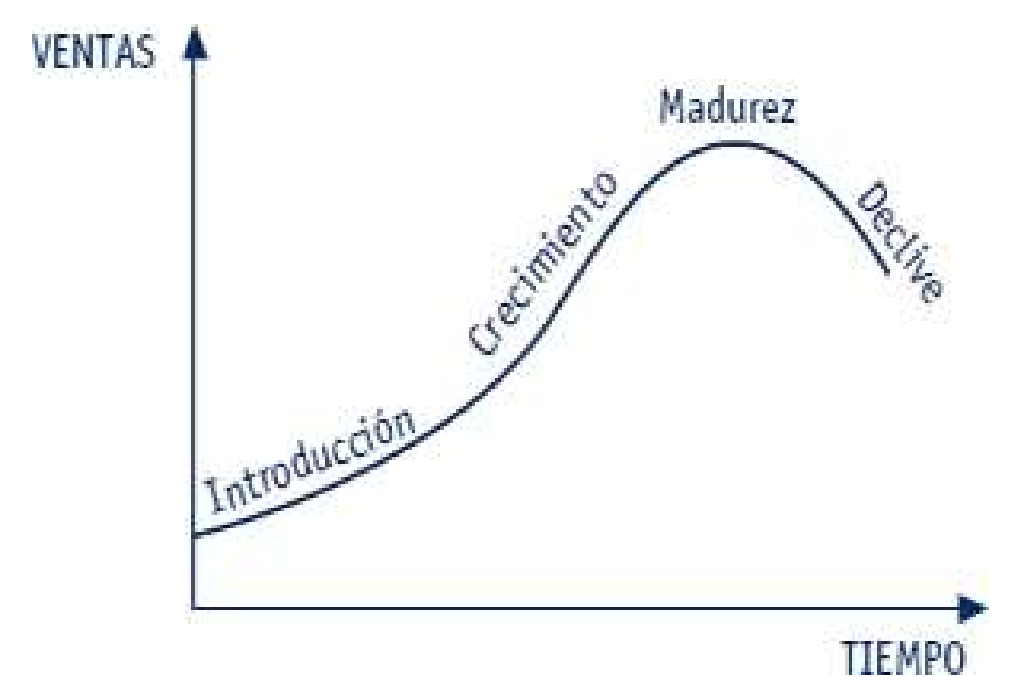

Fuente: mailxmail (2020). Recuperado de
Introducción: crecimiento lento de ventas, no existen beneficios debido a los fuertes gastos que conlleva el lanzamiento del producto.

Crecimiento: aceptación rápida del producto por el mercado en el que los beneficios aumentan considerablemente.

Madurez: ralentización del crecimiento en ventas porque el producto ha sido aceptado por la mayoría de compradores. Los beneficios se estabilizan o bajan por el incremento de la competencia.

Declive: las ventas bajan y los beneficios disminuyen rápidamente. 


\section{Ciclo de vida del producto. Consumidores}

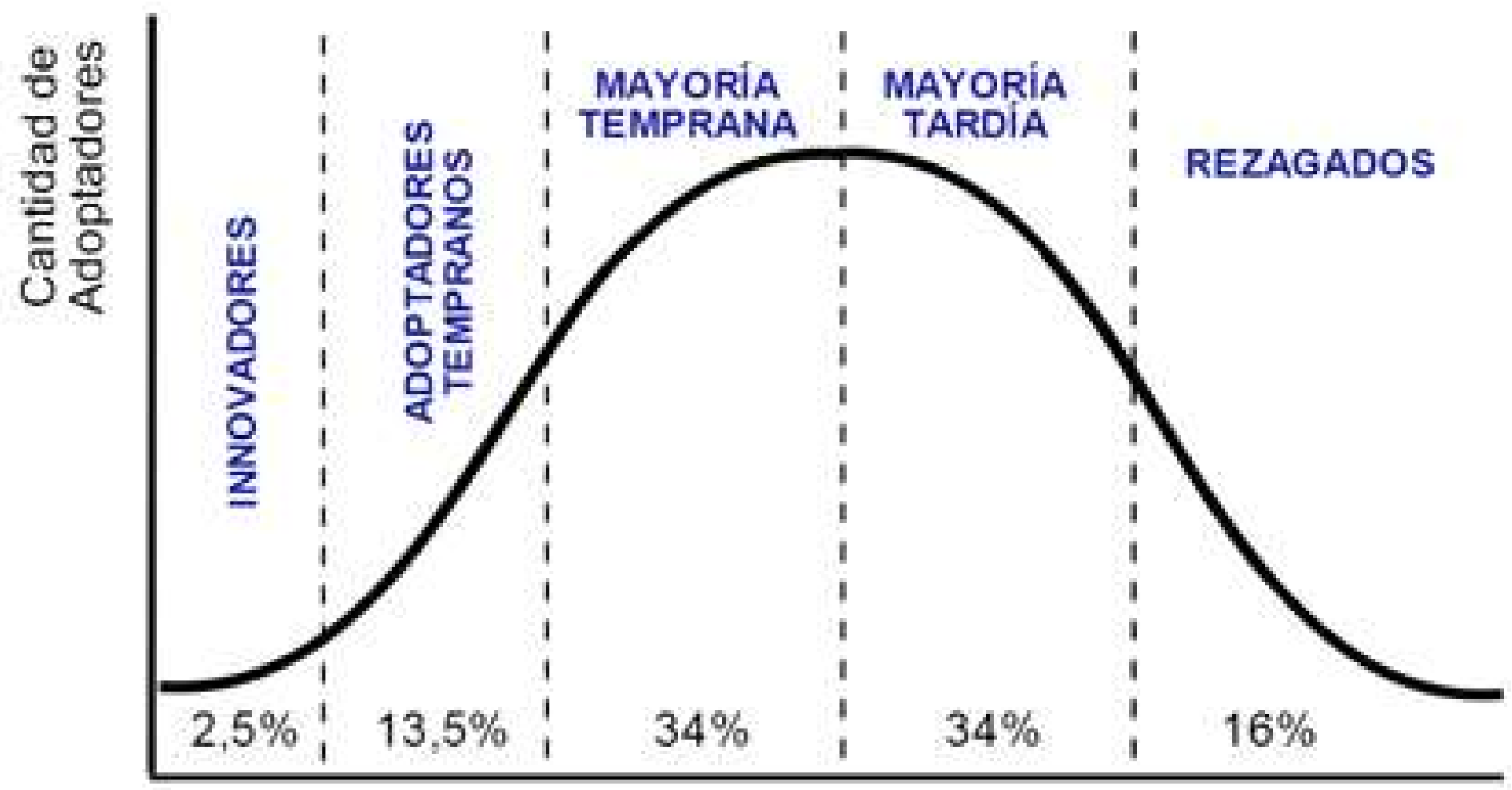

Tipo de Adoptadores 


\section{Ciclo de vida del producto. Consumidores}

INTRODUCCIÓN

CRECIMIENTO

MADUREZ

DECLIVE

$>$ Innovadores. Personas que no les importa el riesgo que comporta un producto nuevo.

$>$ Adaptadores iniciales. Personas más cautelosas, o proclives a la innovación pero sin renta suficiente para adquirir el producto cuando sale al mercado.

$>$ Mayoría temprana. Personas que acogen el producto cuando ya está divulgado y en manos de los líderes de opinión.

- Mayoría tardía. Personas conservadoras, compran cuando la mayoría de los usuarios han comprobado su utilidad y viabilidad.

> Rezagados. Compran cuando la mayoría lo conocen o el precio es bajo. 


\section{Video: The Hula Hoop}

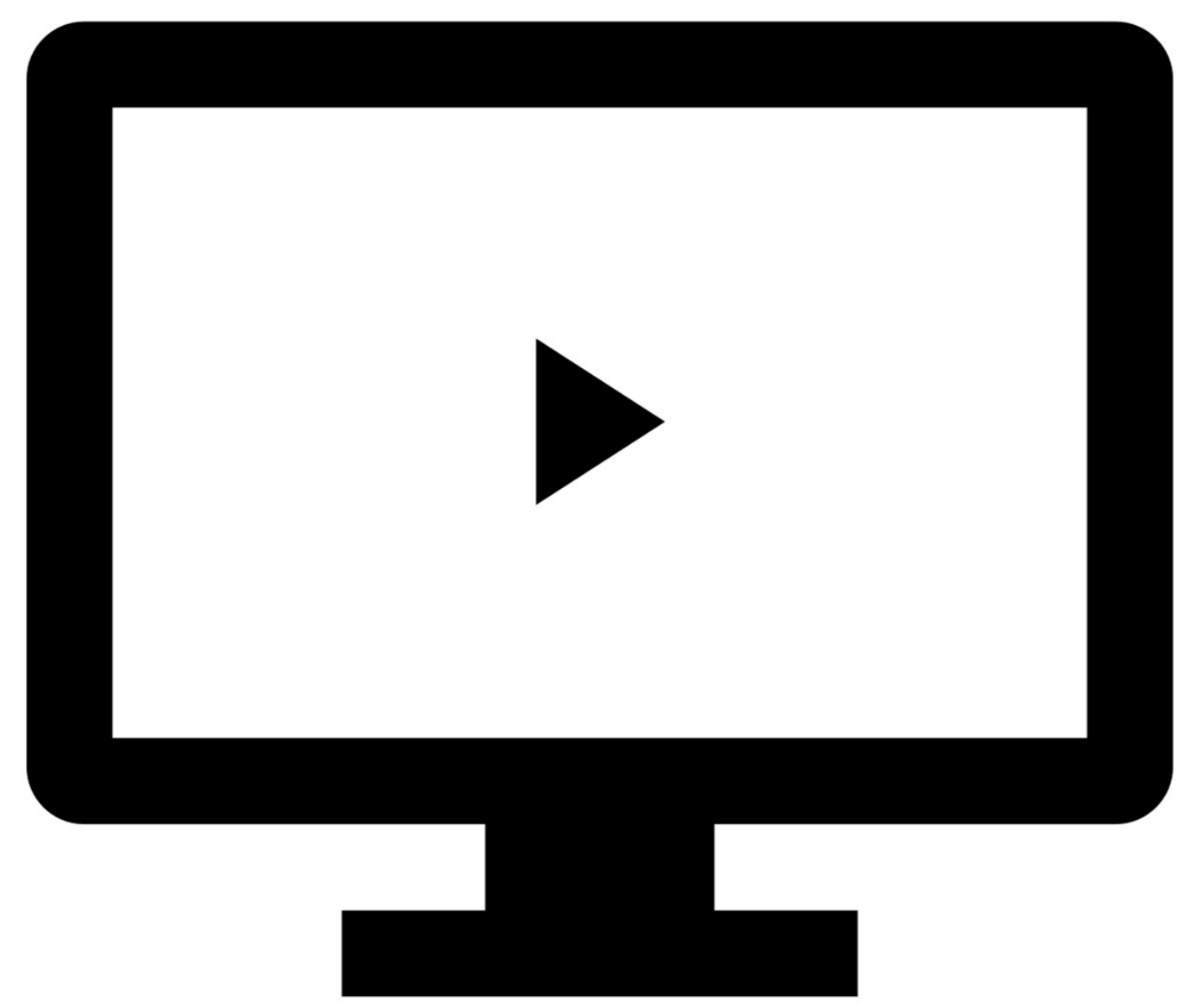

Fuente: Gcm Group (2006, noviembre 29) Hudsucker Proxy, The (1994) Scene.

[Archivo de video]. Recuperado de 


\section{Características de las fases del ciclo de vida:}

\begin{tabular}{|l|c|c|c|c|}
\hline & INTRODUCCIÓN & CRECIMIENTO & MADUREZ & DECLIVE \\
\hline Ventas & Bajas & $\begin{array}{c}\text { Aumentan } \\
\text { rápidamente }\end{array}$ & $\begin{array}{c}\text { Punto } \\
\text { máximo }\end{array}$ & En descenso \\
\hline Beneficios & Negativos & Crecientes & Altos & En descenso \\
\hline Costes & $\begin{array}{c}\text { Alto por } \\
\text { cliente }\end{array}$ & Medios & Bajos & $\begin{array}{c}\text { Bajo por } \\
\text { cliente }\end{array}$ \\
\hline Clientes & $\begin{array}{c}\text { Innovadores } \\
1^{\circ} \text { Adoptadores }\end{array}$ & Mayoría & Rezagados \\
\hline Competencia & Escasa o nula & Creciente & Intensa & Disminuye \\
\hline
\end{tabular}


Otros factores que pueden afectar al ciclo de vida del producto:

$>$ Cambios tecnológicos. Si dan mejores prestaciones al mismo precio o las mismas prestaciones a menor precio aparecen productos más rentables que implican el declive de los anteriores.

> Cambios institucionales. El poder legislativo, ejecutivo y judicial pueden influir en el presente y futuro de un producto. 


\section{Tipos de ciclo de vida:}

1

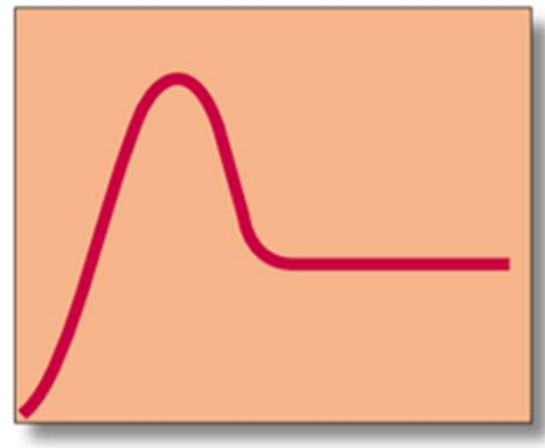

2

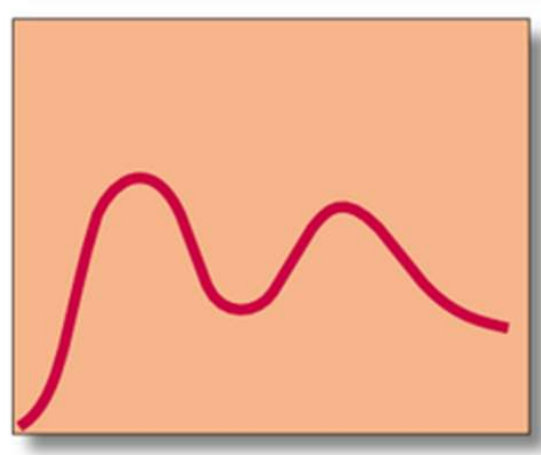

3

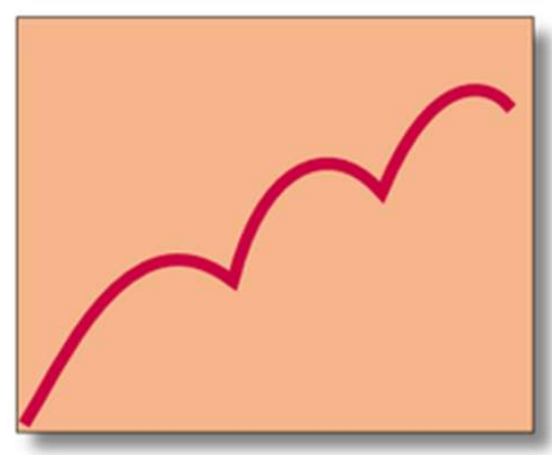

Producto con mercado residual (Bluf).

Las ventas aumentan de forma significativa tras el lanzamiento del producto y después caen hasta llegar a un nivel de "petrificación" gracias a los usuarios primerizos o repeticiones de compra.

\section{Ciclo con nuevas salidas}

Empresa lanza un producto de forma agresiva que genera el primer ciclo y cuando las ventas comienzan a caer, la empresa realiza otra campaña de promoción para estimularlas.

\section{Ciclo escalonado.}

Las ventas atraviesan una serie de ciclos de vida sucesivos como consecuencia del descubrimiento de nuevas características del producto, usos o usuarios. 


\section{Tipos de ciclo de vida}

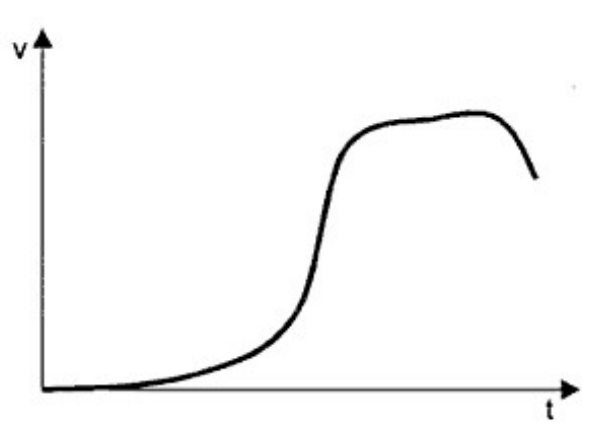

Aprendizaje largo

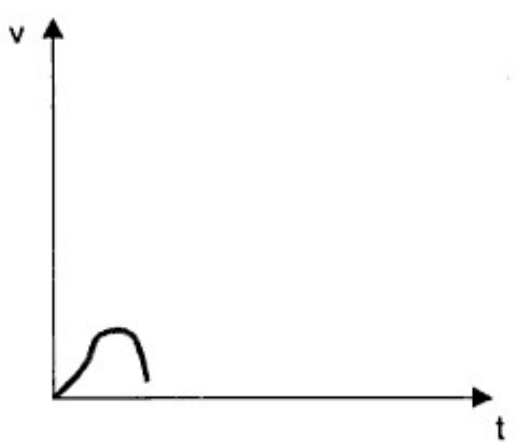

Fracaso

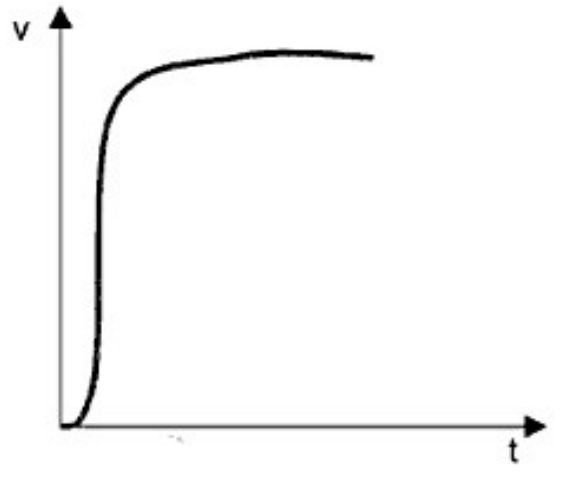

Ausencia de aprendizaje

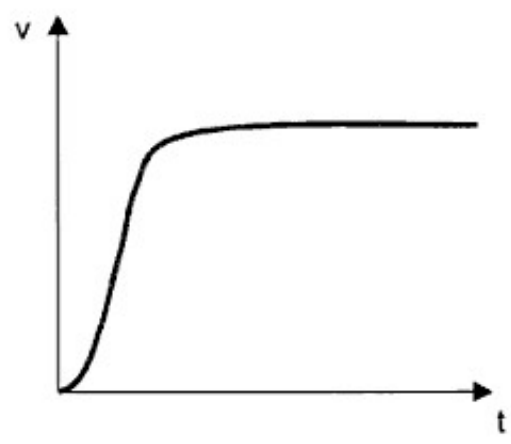

Ciclo prolongado 
2. Análisis estratégico a través del ciclo de vida del producto 


\section{Estrategias de marketing: FASE INTRODUCCIÓN}

\section{Objetivo:}

Crear conciencia sobre el producto y estimular la prueba.

Requiere un alto nivel de esfuerzo:

$>$ Informar a los consumidores potenciales

$>$ Inducir a la prueba del producto

$>$ Asegurarse la distribución en los puntos de ventas 


\section{¿Ser pionero?}

\section{Ventajas:}

$>$ Los primeros usuarios memorizan la marca si satisface

$>$ Determina los atributos que posee la categoría de producto

$>$ Mayor número de usuarios y poder de fidelización, etc.

\section{Riesgos:}

$>$ Productos nuevos demasiado rudimentarios

$>$ Posicionamiento inadecuado

> Apostar antes de que exista una demanda suficiente

$>$ Costes tan elevados que agotan los recursos de la empresa

$>$ Imitadores con producto mejorado

$>$ Incompetencia en la gestión, etc. 


\section{Estrategias de marketing: FASE INTRODUCCIÓN}

\section{Objetivo:}

Crear conciencia sobre el producto y estimular la prueba.

Estrategias:

> Producto:

Ofrecer un producto básico

$>$ Precio:

Estrategia de descremación versus estrategia de penetración 


\section{Estrategias de marketing: FASE INTRODUCCIÓN}

\section{Estrategia de precios:}

\section{DESCREMACIÓN}

- Precios altos

- Se trata de un producto realmente nuevo

- Demanda inelástica al precio

- Demanda sensible a la promoción

- Mercado segmentado

\section{PENETRACIÓN}

- Precio bajo relativo

- El producto no constituye una verdadera novedad (nueva marca/modelo)

- Demanda muy sensible al precio

- Posibilidad de economía de escala u objetivo de recuperación rápida de la inversión

- Amenaza de nuevos competidores 


\section{Estrategias de marketing: FASE INTRODUCCIÓN}

\section{Objetivo:}

Crear conciencia sobre el producto y estimular la prueba.

Estrategias:

> Producto:

> Precio:

$>$ Distribución:

$>$ Comunicación:
Ofrecer un producto básico

Descremación / penetración

Selectiva

Estimular la toma de conciencia en los adoptadores iniciales y los distribuidores 


\section{Estrategias de marketing: FASE DE CRECIMIENTO}

\section{Objetivo:}

Maximizar la cuota de mercado y preferencia de marca

\section{Estrategias:}

> Producto: Variedad del producto y servicios

- Mejora la calidad del producto y añadir nuevas prestaciones

- Fabricar productos de diferentes tamaños, sabores, etc. que permitan defenderse de la competencia y proteger el producto principal.

> Distribución: Intensiva: Aumentar la cobertura de distribución y buscar nuevos canales 


\section{Estrategias de marketing: FASE DE CRECIMIENTO}

\section{Estrategias:}

> Precio:

- Tendencias reguladoras a la baja o alza según descremación/penetración

- Distintos precios para distintas versiones

> Comunicación: $\quad$ Estimular el mercado masivo

- Modificar la actividad publicitaría: de conocer el producto a crear preferencias.

- Mantienen altos gastos de promoción porque tienen que hacer frente a una competencia mayor y continúan educando al mercado 


\section{Estrategias de marketing: FASE DE MADUREZ}

Objetivo:

Maximizar el beneficio y

defender la cuota de mercado.

\section{Estrategias:}

$>$ Producto:

$>$ Precio:

$>$ Distribución:

$>$ Comunicación:
Diversificar marcas o modelos Precio del competidor o inferior

Más intensiva

Insistir en los beneficios derivados de la marca y apoyar los cambios en el producto 


\section{Estrategias de marketing. FASE DE MADUREZ}

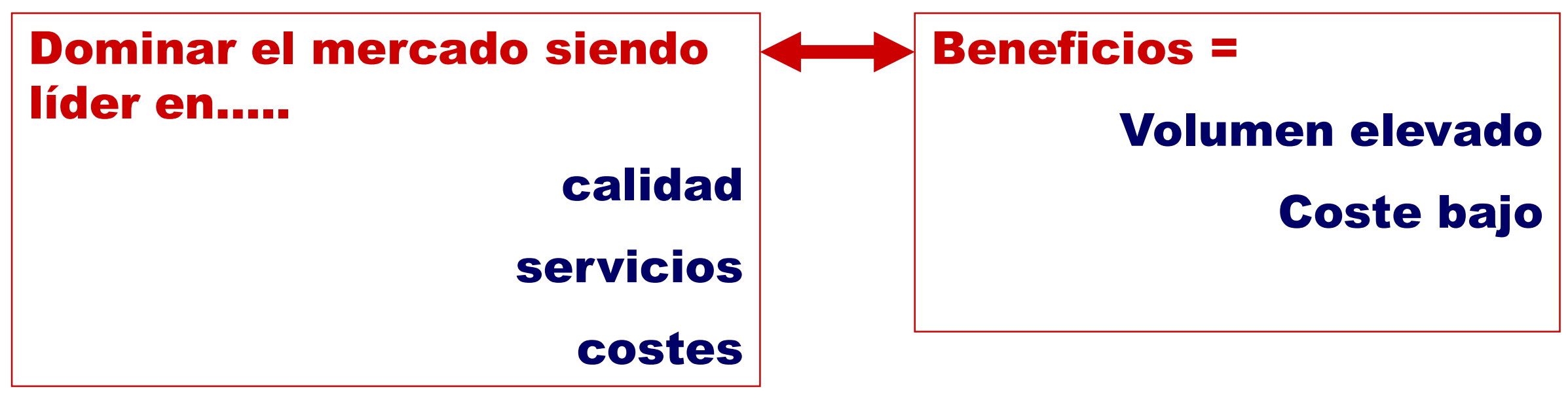

Seguir una estrategia de nichos.....

Especialistas de mercado Especialistas de producto Adaptación total a clientes

Beneficios =

Volumen bajo Margen alto 


\section{Estrategias de marketing: FASE DE DECLIVE}

\section{¿por qué?}

Principales razones:

$>$ Avances tecnológicos

$>$ Cambios en los gustos de los consumidores

> Intensificación de la competencia nacional y extranjera 


\section{Estrategias de marketing: FASE DE DECLIVE}

Objetivo:

Planificar retirada y sustitución.

Mantener productos en fase de declive es MUY COSTOSO. La empresa debe:

> Establecer un sistema de identificación de productos débiles

$>$ Revisión continua de la cartera de productos

$>$ ¿Qué hacemos?

- Mantenerlo

- Modificar la estrategia de marketing

- Abandonarlo

Dependerá del atractivo relativo del sector y de la fuerza competitiva de la empresa 


\section{Estrategias de marketing: FASE DE DECLIVE}

Objetivo:

Planificar retirada y sustitución.

Estrategias:

$>$ Producto:

$>$ Precio:

$>$ Distribución:

$>$ Comunicación:
Eliminar productos débiles

Reducir precio

Selección: eliminar puntos no rentables

Reducir el nivel y mantener a los comunicadores fieles 


\section{Estrategias para alargar el ciclo de vida del producto}


Alargar el ciclo de vida del producto: Estrategias

$>$ Estrategias centradas en el MERCADO

$>$ Estrategias centradas en el PRODUCTO

D Estrategias centradas en VARIABLES DE MARKETING 


\section{Alargar el ciclo de vida del producto:} Estrategias centradas en el MERCADO

$>$ (Incremento de clientes):

1. Captando a los no usuarios

2. Entrando en nuevos segmentos de mercado

3. Quitando clientes a los competidores

$>$ (Incremento de la frecuencia de uso)

1. Promover el uso más frecuente

2. Desarrollar un uso más variado

3. Encontrar nuevos usos para el producto básico 


\section{Alargar el ciclo de vida del producto:} Estrategias centradas en el PRODUCTO

$>$ Mejora de la calidad.

$>$ Mejora de las características o prestaciones

$>$ Cambio en el diseño o estilo del producto que mejora su atractivo 


\section{Alargar el ciclo de vida del producto: Estrategias centradas en MARKETING}

$>$ Modificación del marketing mix: PRECIO

- ¿Bajando precios atraigo a nuevos compradores? SI / NO

- ¿Sería mejor aumentar los precios para transmitir una mayor calidad? SI / NO

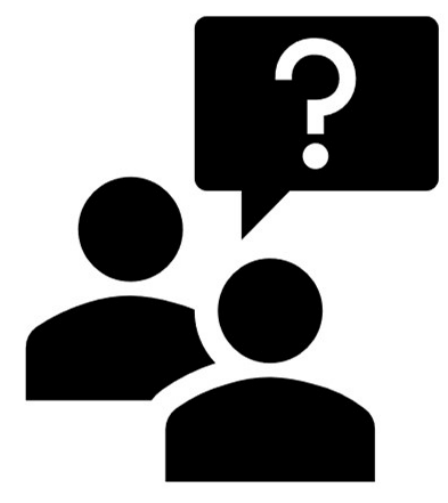

Fuente: Powerpoint, Microsoft 


\section{Alargar el ciclo de vida del producto: Estrategias centradas en MARKETING}

> Modificación del marketing mix: DISTRIBUCIóN

- ¿Podemos penetrar en más puntos de venta? SI / NO

- ¿Podemos estar en nuevos canales de distribución? SI / NO

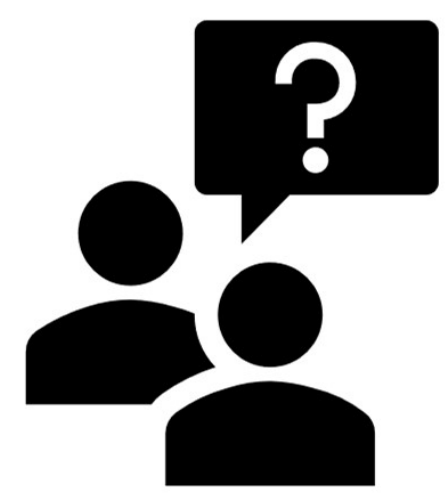

Fuente: Powerpoint, Microsoft 


\section{Alargar el ciclo de vida del producto: Estrategias centradas en MARKETING}

$>$ Modificación del marketing mix: PUBLICIDAD

- ¿Debemos invertir más en publicidad? SI / NO

- ¿Debemos cambiar el mensaje? SI / NO

- ¿Debemos cambiar los medios de comunicación? SI / NO

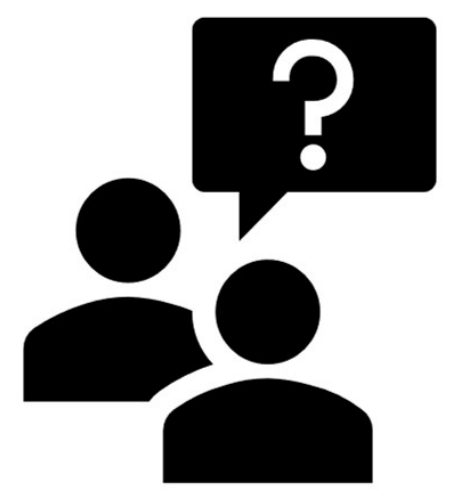

- ¿Debemos cambiar el horario, frecuencia o tamaño de los anuncios? SI / NO 


\section{Alargar el ciclo de vida del producto: Estrategias centradas en MARKETING}

> Modificación del marketing mix: PROMOCIóN

- ¿Debemos hacer descuento comerciales? SI / NO

- ¿Debemos realizar regalos? SI / NO

- ¿Debemos realizar concursos? SI / NO

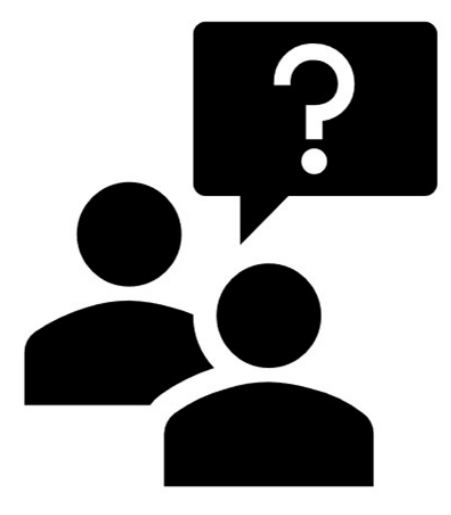

Fuente: Powerpoint, Microsoft 


\section{Alargar el ciclo de vida del producto: Estrategias centradas en MARKETING}

$>$ Modificación del marketing mix: PERSONAL

- ¿Debemos aumentar la cantidad y la calidad de los vendedores? SI / NO

- ¿Debemos tener personal especializado? SI / NO

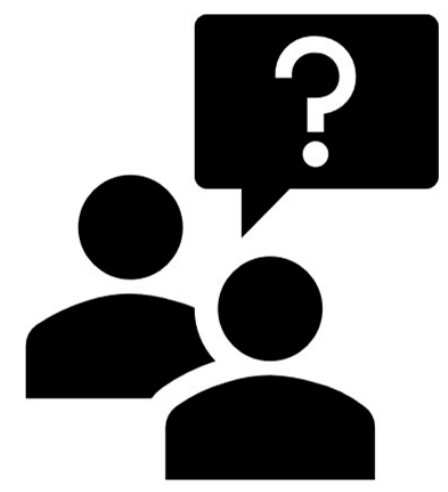

- ¿Debemos replantearnos el territorio de ventas? SI / NO 


\section{Alargar el ciclo de vida del producto: Estrategias centradas en MARKETING}

> Modificación del marketing mix: SERVICIOS

- ¿Podemos realizar entregas más rápidas? SI / NO

- ¿Podemos incrementar la asistencia técnica a los clientes? SI / NO

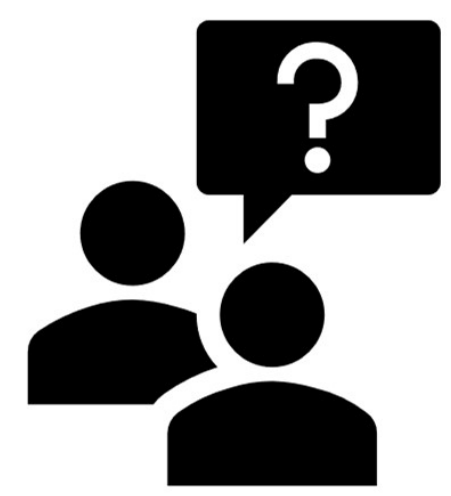

- ¿Puede la empresa conceder más garantías? SI / NO 


\section{El ciclo de vida del producto}

1. Concepto y características del ciclo de vida del producto

2. Análisis estratégico a través del ciclo de vida del producto

3. Estrategias para alargar el ciclo de vida del producto

Inmaculada Gallego Galán

igallego@uma.es

Dpto. Economía y Administración de Empresas 